\title{
Ageism and Illegal Immigration in Margaret Drabble's The Dark Flood Rises: An Affect Theory Approach
}

\author{
Hanan Barakat, PhD \\ Associate Professor of English Literature \\ Department of English Language \& Literature \\ Faculty of Arts, Helwan University \\ hananbarakatd@yahoo.com
}

\begin{abstract}
The present study attempts an affect theory reading of Margaret Drabble's The Dark Flood Rises (2016). It targets the representation of the two issues of ageism and immigration in the novel and the writer's purpose of representing these cases. The representative characters of these cases are British, Anglo-Egyptian, and Senegalese. The media's bleak representation of these cases and its impact on the audience's attitude is handled as well as the counterpart played by fiction writing to affect a better awareness of ageism and immigration. The two affects focused on are sympathy and empathy; their nature and the social conditions that lead to the simulation of each are highlighted. The different narrative methods employed in these simulations are investigated. The study also attempts to find out why the author does not target the simulation of only one of these affects, either sympathy or empathy, in her portrayal of the characters who represent ageism and immigration.
\end{abstract}

\section{Keywords}

Sympathy; empathy; media; ageism; immigration; in-group; outgroup. 


\section{Ageism and Illegal Immigration in Margaret Drabble's The Dark Flood Rises: An Affect Theory Approach}

Margret Drabble (1938 --) is one of the prominent contemporary English writers whose work includes both fictional and non-fictional writings. In addition to her novel writing, Drabble wrote biographies of Arnold Bennett and Angus Wilson, works of criticism such as A Writer's Britain: Landscape in Literature, and edited the fifth and sixth editions of The Oxford Companion to English Literature. Jose Francisco Fernan aptly describes Drabble and her literary achievement as "the social writer par excellence of her generation and the presence in her work of an artistic impulse that has always been open to evolution and transformation" (1). She began her writing career with the novel A Summer Birdcage, which is followed by many other novels and short stories that tackle a wide range of social, economic, and artistic issues. Her 1960s and 1970s novels reflect feminist interests: the struggle of career-women, motherhood, conflict between aspiring young women and social conventions. From 1980s up to the early years of $21^{\text {st }}$ century, her novels tackle other feminist issues such as women academic life and female relationships. Recently, Drabble has tended to write novel with wider social and global issues of ageism, immigration and environmentalism. The range and evolution of her novel reflect a willingness to both represent and take part in social and political transformation as will be presently discussed.

The Dark Flood Rises (hereafter Dark Flood) is a novel that tackles the issues of ageism and illegal immigration. In introducing the book, Drabble, most probably inspired by her age, focuses on the theme of ageing, she expresses her belief that "it is very necessary and important to talk about ageing. Death will happen, but ageing happens in so many ways and society must learn to think clearly about how we age, how we care for our ageing population, which gets larger and larger..." (Bertrand Editora 001:30-002:23). The novel is more character-driven than plot-driven; the psyche of most of the characters is delved into, whereas their external action is less focused on. Since most of the characters are in their old age, the narrative is often retrospective as their thoughts and memories dominate the novel. Dark Flood is told from the different viewpoints of most of the characters who are either friends or related by blood or marriage. The narrator moves with the characters from England to the Canary Islands and back again, as each reflects on her/his different life experiences. The heroine Francesca (Fran) Stubbs is in her seventies, and mostly preoccupied with ageing 
and death, but mortality concern does not hinder her from living an active and busy life. She inspects care homes for the elderly which allows her to drive around England, prepares home-cooked dinners for her ex-husband, and is always ready to offer help to her independent middle-aged children. The book ends by reporting the death of many of the characters and offering a gleam of hope of improving the situation of immigrants.

The literary scene has always been engaged with a host of diverse literary theories that aim to offer different readings of creative works. Beginning with the twenty-first-century affect theory has been progressing toward the foreground of critical theory and literary studies scene. The theory is based on the notion that "no embodied being is independent, but rather is affected by and affects other bodies, profoundly and perpetually as a condition of being in the world" (Ahern 4-5). Affect theory helps toward grasping how and why affective intensities -represented by basic emotions such as sadness, anger, fear, happiness which are evoked by different stimuli -- motivate certain attitudes towards others. The theory, as Kanta Dihal further elaborates, "explicitly addresses that hard-to-grasp concept of what moves and motivates people ... it goes beyond mere emotion, as it analyses how and why people are physically and mentally changed by interactions with others and with the objects they encounter" (2). Affect theory is gaining ground due to the ongoing research in the field of neuroscience, and studies in diverse disciplines of humanities.

Affect is relevant to emotion, in the field of psychology, it is defined as, "the collective term for describing feeling states like emotions and moods. Affective states may vary in several ways, including their duration, intensity, specificity, pleasantness, and level of arousal, and they have an important role to play in regulating cognition, behavior, and social interactions" (Niven 49). Nature and the vital part played by emotion in cognition are acknowledged by the empiricism of psychology and neuroscience. Unlike the common tendency to foreground and prioritize reason to emotion, which goes back way beyond the Enlightenment, these contemporary disciplines aim to establish a balance between reason and emotion.

In her ground-breaking article "The Turn of Affect," Ruth Leys dismisses the general philosophic tendency to overvalue reason; she points out that human beings are corporeal; they are

Creatures imbued with subliminal affective intensities and resonances that so decisively influence or condition our political and other beliefs that we ignore those affective intensities and resonances at our peril-not only because doing so leads us to underestimate the political harm that the deliberate manipulation of our affective lives can do but also because we will otherwise miss the potential for ethical creativity and transformation that "technologies of the self" designed to work on our embodied being can help bring about. (436) 
Reason should not be conceived as the major entity that shapes our views, beliefs, and decision making; there are affective intensities that also take part in processing and creating them. The overvaluing of reason at the expense of these affective powers has allowed the self-interest group to manipulate us into beliefs and decisions that would be in their best interest. These manipulators appeal to "affective intensities and resonance" that play a decisive role in forming and developing our beliefs, thus we lose part of our agency that help us toward independent creativity.

On the other hand, Patricia Ticineto Clough explains why focusing on affect corresponds to current world affairs.

The increasing significance of affect as a focus of analysis across some disciplinary and interdisciplinary discourses is occurring at a time when critical theory is facing the analytic challenges of ongoing war, trauma, torture, massacre, and counter/terrorism. If these world events can be said to be symptomatic of ongoing political, economic, and cultural transformations, the turn to affect may be registering a change in the cofunctioning of the political, economic, and cultural ... (1)

Humanity has always experienced wars and their catastrophic aftermath, but what distinguishes the past from the present is that in the past wars had a limited scale of destruction and bloodshed. Whereas in the present, and starting with WWI, political decisions taken by very few leaders often prove to have a huge worldwide catastrophic impact both on man and the environment. The foregrounding of affect theory as the right and suitable one to approach current global transformational events does not mean its total independence or separation from other disciplines. The theory draws on disciplines such as philosophy, psychology, and cognitive science. Concerning philosophy, Baruch Spinoza is believed to be the philosopher "who has advanced furthest the theory of the affects and whose thought is the source, either directly or indirectly, of most of the contemporary work in this field" (Hardt ix). Many affect theorists draw on Spinoza's views on how the body can affect things and be affected by them, and the outcome of this interrelationship. As for psychology, it is Jacques Lacan's psychoanalytic ideas on anxiety that are often drawn on in affect theory studies. And as Suzanne Keen affirms, "the recent interest in the role of affect in cognition ... has brought emotion back into the critical conversation" (xi).

Reading fiction is hoped to improve and strengthen human relationships. Sklar asserts that "Fiction's role . . . has come to be seen . . . as a facilitator of that connection, a way of enabling readers to extend their feelings and ways of thinking beyond themselves" (451). Reading about the suffering of fictional characters is expected to inspire and motivate readers to take part in alleviating the suffering of others. Achieving this stage is explained by Dana LaCourse Munteanu in her illuminating study "Empathy and Love: Types of Textuality and 
Degrees of Affectivity," in which she elaborates on how reading fiction helps us toward "achieving insight into the thoughts and emotions of others" (325). She uses the term "aesthetic emotion" to refer to the arousal of our emotions when we read fiction and feel moved by its world, as well as emotion incorporated into the literary or artistic works. Munteanu compares our response to fictional tragedies to that of tragic news stories such as those of killed soldiers. She notes that we are more moved and shaken by fictional tragedies than the real ones; our brain needs coherent narratives to "connect certain situations to affective states," which the news does not offer. Instead, it offers us brief accounts of a particularly tragic case, then shifts to another piece of news. The brief time on which the news is shown does not allow us to engage with the suffering of the people in the news. Also, we are not detailed with the private life and thoughts of these people. Whereas fiction allows us into the minds of the characters; their internal perspective is exposed, which leads to "temporal imaginative investment" in the suffering of characters. Yet, Munteanu remarks that our aesthetic emotions do not enable us to take actions "to alleviate pain." She explains that owing to the imaginative nature of fiction, the arousal of readers' empathy does not help in improving characters' emotional problems. Munteanu expresses her wish that "If we could bring the quality of emotion-arousal from great literary texts to real-life cases, then, perhaps, this could further lead to social action" (328). The literary simulation of readers' sympathy and empathy, which will be presently discussed, represents a step forward in achieving positive social change.

Emotion is vital to literature; fictional works represent different emotions such as love, jealousy, rage. In acknowledging the important role of emotion, Patrick Holm Hogan proposes a thorough investigation of its vitality, "Beyond treating different theories of emotion, an account of literary affect needs to consider the various possible locations of emotion in literature" ("Affect Studies"1). Authors, utilizing the narrative technique, often manage to manipulate readers into experiencing certain emotions, responses, and attitudes towards characters. Affected by these reactions, readers either empathize or sympathize with characters who undergo diverse intense experiences.

Sympathy and empathy are two terms that have often been confused. The term Sympathy is included in the 2013 edition of Cuddon's Dictionary of Literary Terms, but an entry is not provided, instead, its definition is included in the 'Empathy entry. Alternatively, Sklar emphasizes the comparatively late emergence of term 'Empathy' by noting that it is "created as recently as the beginning of the twentieth century" ("Empathy Neglected Cousin" 451-452). Hence, it can be claimed that the two terms are prioritized differently by scholars. In justifying these different prioritizations, Martha Nussbaum points out that "sympathy" and "empathy" ... appear in texts and in common usage, usually without clear distinction . . . from one another" (301). The conflation of the two terms even goes farther back to the $18^{\text {th }}$ and $19^{\text {th }}$ century when, as Suzanne Keen 
states "aspects of empathy have been described by philosophers since the days of Adam Smith and David Hume under the older term sympathy" (4). The source of confusion between the two terms is partly attributed to the fact that they deal with and indicate people's sharing feelings for one another. However, the disciplines of social psychology, neurology, literary criticism, in particular affect theory, have focused on sympathy and empathy and treated them as two different emotional states. As a result, there is a growing number of illuminating studies that give a detailed and thorough explanation of the nature of each. In the field of psychology, empathy is defined as an "emotional state triggered by another's emotional state or situation, in which one feels what the other feels or would normally be expected to feel in his situation (Hoffman 440). Whereas sympathy is defined as "an other-oriented emotional reaction (such as concern) to another's emotional state or condition" (Eisenberg et al. 55). Sklar notes that sympathy "involves greater distance between the individual who feels it and the person towards whom it is directed" (The Art of Sympathy 26). What is common between these definitions is that both empathy and sympathy indicate an emotional state which relates one person to another; one person feels for the suffering of another. But empathy indicates that a person identifies with the suffering of another person, or puts himself in the shoes of that person, whereas sympathy involves a kind of emotional distance between the sympathizer and the person who suffers.

Another difference between sympathy and empathy is that the former is judgmental and the latter conditional. Sympathy, which Nussbaum ("call[s] compassion" (310) is regarded by her as "a painful emotion occasioned by the awareness of another person's undeserved misfortune" (310). This view indicates as Sklar notes "the notion that the emotion frequently involves the recognition that the suffering of another is undeserved or even unfair, an awareness that requires a judgment or evaluation based on particular assumptions regarding what is "deserved," "fair" or "just" - in other words, based on particular moral conceptions or sensibilities" (The Art of Sympathy 28). The sympathizer views the distress of the sympathized person and its causes within a framework usually informed by certain forms of values such as social, moral, and political. Based on these values, diverse sufferings are decided as undeserved or otherwise. On the other hand, the conditionality of empathy, as Thomas Blake explains, echoes the sentiment that "our movement toward others may be blocked as we drift toward familiarity or moral certainty" (220). Familiarity with the person who suffers simulates our empathy; we tend to identify and empathise with those whom we share common characteristics such as race, ethnicity, religion.

Simulation of either sympathy or empathy is based on categorizing people into in-group and out-group. Hogan sums up the difference between these groups as follows, "In-groups are groups with whom one shares some social identity. Out- 
groups are groups that do not share that identity" ("Social Identity" 190). In-group people are those whom we share a common ground of race, land, ethnicity, language, but out-group people do not share these characteristics. Meanwhile, these characteristics decide acceptance or rejection of in/out groups by one another; they either unite or divide people. Recognition of these groups is easy and almost instant; studies in both psychology and neurobiology show, as Hogan notes, that "we categorize individuals very quickly in terms of at least certain ingroup/out-group divisions, prominently those that involve high visual salience" ("Understanding Nationalism" 30). Race, colour, language, even clothing, are but some of the salient characteristics that our senses of sight and hearing help in distinguishing between in-group/out-group.

Neuroscience sheds light on our recognition of in-group/out-group by explaining how the brain receives signals of acceptance of in-group. Blake sums up these findings as follows.

Neuropeptides are molecules that transmit a variety of signals to the brain that initiate or terminate activity. Oxytocin, a neuropeptide produced in the hypothalamus and stored in the pituitary, triggers "recognition of subtle social signals encoded in facial expressions" and has been found to play a significant role in empathy insofar as it "promotes social approach behavior and reduces the tendency to avoid proximity with unfamiliar others." The release of oxytocin increases our willingness to trust others, thereby creating the pleasurable state of being more "at ease" which mitigates the natural anxieties we experience when confronting difference. (219)

These neuro-signals help toward reducing stress while dealing with in-group members; once a common ground is established, these members experience a close and harmonious relationship. Alternatively, out-group compel feelings of contempt and disgust. In examining these negative responses, neuro-studies have shown that the activity of the amygdala, a mass of grey matter inside each cerebral hemisphere and involved with the experiencing of emotions, increases when confronting others who are different in race or otherwise. Researchers interpret "differences in amygdala activity to other-race faces as evidence of negativity (including disgust and fear) toward stigmatized groups" (Cikara and Bavel 248). This neuroscientific phenomenon justifies aversion to out-group members, meanwhile, a propensity to deal with ease with members of in-group. Furthermore, Hogan sees that our distrust of out-group members leads to seeing these people endowed with some power which we don't have. However, if this out-group is "inferior in power" our emotional response shifts from "otheraggrandizing and self-diminishing emotions ... [into] self-aggrandizing and other-diminishing emotions" ("Social Identity" 197). These unfavourable responses ruin relationships and lead to social exclusion. Hence, diverse studies of in/out groups interactions aim to reduce group division and bias. The characters 
in Dark Flood are divided into in-group and out-group; the division is mainly based on their age group and race.

Ageism and illegal immigration are two pressing cases that impact the political and social atmosphere of Europe. The media's representation of social, economic, and health issues of the ageing population is driven by the growing number of senior citizens. Dark Flood is a novel about ageism in England and illegal immigration to Europe. The characters who represent longevity are English, in-group, and those who represent immigration are out-group, either African or of mixed race. But before dealing with the representation of these issues, it is thought that a brief review of their representation by media is relevant.

To begin with, the issue of ageism is one that has become globally important due to the increase of the ageing population. First, it should be pointed out that the general social attitude towards senior citizens often proves negative. The reason for this is the general belief that "the share of older recipients of services increases, so will their dependency on the working population, since the number of employed individuals will remain steady or decline" (Cristea et al. 2). The conception that ageism is an economic burden has led to a further deterioration of the social and economic position of the elderly, namely, age discrimination. Senior citizens are often affected by these negative social attitudes that are based on the conception that they are no longer capable of taking an active part in the welfare of the nation. Further, these attitudes prove to have a negative impact on how the elderly see themselves, and on their belief in their capability, which eventually leads to their withdrawal from society. In her report to the UK government which suggests creative ways to attract and retain older workers, Ros Altmann notes that "Age discrimination and unconscious bias remain widespread problems in the UK labour market and more action is needed to overcome this" (6). The sound strategy to reduce this bias is to allow the elderly to regain their position in the workplace and work with workers of the younger generations, indeed, sacrificing the long-term gained experience of older workers because of age discrimination represents a serious loss to the market.

On the other hand, media has had its part in promoting public negative stances on ageism. As Anne Cornelia Kroon and her colleagues point out, "The visibility of older workers in the news media was associated with higher levels of age discrimination claims. . . News media's attention for older workers' problematic health status was associated with higher levels of age discrimination claims" (116-117), in consequence, defenders of senior citizens' rights demand "a more critical response to the way older adults are represented in the media challenging the impression that older people are merely consumers of finite resources" (Swift et al. 9). These negative views, of the media and society alike, overlook individual physical and mental differences among older people. Some remain capable of contributing to the welfare of their countries far beyond the formal age of retirement set by the state. Hence, senior citizens' withdrawal from 
workplace causes a serious economic loss. Indeed, all these negative stances have been brought into the parliamentary discussions and MPs expressed "a pressing need to change the approach to population ageing and to adjust policies accordingly" (Parliamentary Assembly para. 2).

In Dark Flood, the heroine Fran represents ageism and the preoccupations of senior citizens. Fran's thoughts on her ageing are spilt out both spontaneously and explicitly, the narrative method employed here is focalization. Don K. Philpot defines this method as a "concept and heuristic framework that enables readers to explore personal fictional world experiences and their meanings, meanings that focus on the perceptual, psychological, and social-psychological experiences of one fictional world individual" (11). These revelations are achieved by different forms of thought presentation: direct thought, thought report, and free indirect thought, which, as Sklar points out, "essentially places readers inside the experience-and particularly the emotional experience-of that character" ("Empathy's Neglected Cousin" 458). These thought presentations are employed to facilitate and accelerate readers' access to Fran's mind, thus, helping readers to put themselves in Fran's shoes which, as explained earlier, simulates empathy.

The very opening lines of the novel offer Fran's contemplations over "her last words to herself and in this world" (Drabble 1). Her preoccupation with death is further confirmed by the narratorial voice telling the reader that, "Fran had from an unsuitably early age been attracted by the heroic death, the famous last words, the tragic farewell" (4). The narrator elaborates on the notion of the last words of dying famous people such as the Renaissance poet Walter Raleigh and the $19^{\text {th }}$ century English social theorist Harriet Martineau. The shift from the voice of the narrator to that of the protagonist is swift and unnoticed; often the two voices are integrated that it is hard to tell which is which. Fran often recalls stories and incidents of old people who either suffer marginalization because of their frailty or remain defiant to their age by leading an active life, she prefers the latter option. Despite her preoccupation with death, Fran feels "not ready to settle yet, with a cat upon her knee" (24), she is determined to resist age frailty. Her age and apparent preoccupation with death do not stop her from playing an active and significant role in the lives of her fellow old people who need care. She "is employed by a charitable trust which devotes generous research funds to examining and improving the living arrangements of the ageing" (3). Fran takes her work seriously; she conducts her care homes' inspection tours "driv[ing] around England" (5), mostly alone. Her views on diverse issues are revealed as they alternate with her contemplations on death.

Fran is also concerned for her family, her two children, Christopher, a TV presenter, and Poppet, who is overwhelmed by ecological interests. But Fran is keen to stop short before intruding on their life; she constantly reminds herself of the necessity of "The keeping-in-touch without-being-too-annoying with her son Christopher and her daughter Poppet ..." (Drabble 49). She is well aware that they are no longer in need of her services, but she is also keen on maintaining the 
family bond by keeping in touch with them either by texting or occasional brief meetings. Fran's concerns extend to her ex-husband, Claude, their short marriage which lasted for four years, and the fact that they had been divorced for almost fifty years does not stop her from preparing him "wholesome meals" now that he is "physically somewhat imprisoned" (25). Such care leads to raising questions on how, despite their short marriage, Fran insists on looking after him. In her analysis of readers' positive attitudes to characters, Keen says "When we respond empathetically to a novel, we do not have the luxury of questioning the character: we cannot ask, Is that how you really felt?" (136). Lack of direct communication between readers and fictional characters leaves readers with unanswered questions; finding answers justifies, or even enhances, empathetic responses. Keen further elaborates by pointing out that "The text, however, may verify our reactions even as it elicits them. Some narrators employ psycho-narration, or generalizations about the characters' inner states, including thoughts and feelings, with the result that the text itself announces how the character feels" (136). Thus, lack of direct communication with characters is compensated for by these internal perspective expositions. For instance, the reader realizes that Fran's decision to undertake this catering mission at late age does not mean that she owes her exhusband a debt of gratitude, on the contrary, her memories of their marriage are bleak.

He used to get back from the hospital after the night shift, and she'd have made the healthy thrifty chunky soup and all he had to do was warm it up. But that wasn't good enough. HER to be there to WARM IT UP FOR HIM. And she in bed and worn out with children sleeping or not sleeping or waking or not waking and the sense of unutterable inadequacy, the sense of rejection, the fear, the panic ... you'd think she'd have grown out of it by now, by her age, at seventy-plus, but no, it intensifies, it gets worse and worse. (Drabble 45)

Fran's hard feelings are caused by the long nights she spends alone looking after the children, her husband's bad temper, and selfishness. Though her memory portrays events that occurred four decades earlier, Fran's pain and sense of suffering still linger as the use of the adverb 'now' indicates; it creates a sense of immediacy that connects the past to the present. These sorrowful nights are not represented as happening now, instead, they are replaced with Fran's thoughts and emotions. The effect of this replacement on readers, as James Phelan explains, is allowing "entering into the speaker's situation and perspective without judging it. That participation, in turn, influences the affective side of the experience-we share the speaker's feelings or take on the speaker's thoughts, beliefs, or attitudes" ("Experiencing Fiction" 152). Fran's internal focalization, as mentioned above, allows readers easy access to her thoughts, memories, contemplations and emotions. Thus, readers do not judge her according to her actions and what she says, or even how she deals with others. Her motivations, 
experience, and attitude towards others are taken into consideration; these help in justifying her decisions and actions. In consequence, empathy is created and the reader is aware of what motivates her to make certain decisions such as divorcing Claude.

Further, Fran's troubled marriage has affected her maternal behaviour. She remembers taking to drink which has led to suffering violent fits. Her children also remember dreading these fits and learning how to avoid them by "stay[ing] upstairs, out of harm's way" (Drabble 78). Fran's heavy drinking, which provides her with a temporal escape from her miseries, has led up to aggressive behaviour. These episodes "had been frightening" for her children, and just like Fran's unpleasant marriage memories, they become part of the children's shared and often recalled memories. Yet, the effect of these moments on Fran's image becomes milder as accessing her internal perspective reveals her reasons for such maternal aggression, thus, readers' empathy with her is still maintained.

Illegal immigration is the second issue represented in Dark Flood. The political reasons that lead to waves of immigrants attempting to reach European shores are either alluded to or discussed amongst characters. Illegal immigration has been there for a long time, but the political turmoil in the Middle East, aka the Arab Spring, in addition to a series of military and economic crises in Africa, have pushed it to an unprecedented level. Footages of boats carrying men, women and children who desperately try to cross the Mediterranean seeking better life in Europe have been occupying the media and often been foregrounded against many other current affairs news.

Public attitude towards immigrants and their cause is largely shaped by media, Victoria Danilova asserts the view that globalization has led to empowering media as to become one of the major factors that currently affect public opinion. Easy and instant access to news websites has helped towards audience being informed about the issue. Meanwhile, media also shapes the image of immigrants, as Eberl et al. have noted, "Salience of immigration issues in media coverage eventually influences audiences' political attitudes" (217), since the majority of the audience do not have a first-hand experience of these immigrants, they become greatly dependent on media for information on the subject. Thus, the source of information, that is media, finds it easy to form an audience attitude towards immigration issues. On her part, Danilova focuses on the language used by media which tends to 'other' immigrants; she sees that this estranging language both shapes and echoes public perception of the issue. Further, attitudes towards immigrants, "reflect a negative out-group bias" (Brosius et. al. 449), thus, "they are present in the media, they are often framed as either economic, cultural, or criminal threats" (Eberl et al. 217). These negative stances to immigrants, the out-group, lead many Europeans to oppose plans of hosting some of them, even if the hosting is intended to be only temporal. 
Against the grain of media's role in shaping the audience's negative attitude toward immigrants, Dark Flood offers a narrative that counteracts such underrepresentation. The media's interest in shooting footage for desperate immigrants, and the impact of the case on European domestic and foreign policies set the stage for Sara and Ishmael cases in the novel. Sara, who is only referred to in the novel, due to her early death, is an Anglo-Egyptian smart young woman who adopts the case of immigration. She prepares for a documentary that highlights the issue to be broadcast on TV. Ishmael is a Senegalese young man who, unlike many of his fellow immigrants, survives the sea voyage from African shores and ends up being adopted by a Spanish intellectual who lives on one of the Canary Islands. Thus, it is clear that these two characters are associated with a set of affective responses to the flow of immigrants arriving, or failing to arrive, to European shores.

Sara Siddiqui dies before finishing her media project; the documentary has been intended to present the other side of the immigration story, the risky and often deadly voyages. She visits different ports that are known for either sending or receiving African immigrants whose cause seems to be her lifelong mission. She travels to the Canary Islands with the hope of making a documentary on destinations of illegal immigration, and to have "its silent dead . . . speak" (Drabble 70). European ex-pats who are interested in the case help her in the mission which also seeks the protection of immigrant minors. Sara's character and her enthusiasm for the cause of immigrants and hard work on the documentary are admired by all European characters in the novel.

On the other hand, Sara's character, and her intellectual superiority to her English partner, Christopher, is often evoked both by him and his mother, Fran. Christopher admits that

She had been ... powerful ... too serious for him ... Her subjects had been too big for him. . . the rusting ships ... the immigrants wrapped in gold foil ... She had been too many for him ... .He wasn't up to her level ... She had been an alpha female, and she had outclassed him. (Drabble 269)

Regarding Hogan's categorization of identities, and the subsequent attitudes of in-group towards out-group, the Anglo-Egyptian Sara is of mixed race, so, she is not a fully in-group member. Hence, she is liable to evoke diverse emotions of threat, contempt, inferiority, or "other-aggrandizing and self-diminishing" emotions. According to the above-quoted passage, Christopher's reflections on her are aggrandising. Though he too is a TV presenter, he feels her superiority to him because of her "powerful" character and preoccupation with wider cosmopolitan issues. 
The other-aggrandizing emotion is not limited to Sara's representation, Ishmael, an African immigrant, and an out-group member is also meant to simulate positive emotion. And, if Sara's documentary aims to offer a panoramic view of illegal immigration, Ishmael represents the story of individual immigrant survival. Not much details about this young Senegalese are provided, and what is told seems to be carefully selected to reveal the high-cost immigrants offer to reach European shores. Ishmael's story is told in fragments: leaving his country, the sea voyage, adoption by a European intellect, and his plans for a better life. Like many other similar ships, Ishmael's is wrecked, but he survives. It is noteworthy that Ishmael is represented to the reader with an atmosphere of grace and elegance; he is described as "very photogenic" (Drabble 72), "fine-looking young black man ... . speaks good French and English" (138-9). The young African also studies "IT online, with an American university programme" (140). However, being a member of an out-group: non-European, Ishmael is bound to be conceived as a source of threat. But the description given to him reduces that negative response. These few positive characteristics shorten the distance between the African immigrant and the European reader; he is more appealing when depicted as handsome and smart. His "inferiority" as a member of out-group "is not blameworthy," he is not to be blamed for being non-European, on the other hand, the fact that he studies IT proves his ambition and determination to lead an independent life, rather than being an economic burden on the host country. His choice of the field of programming, as a rapidly developing science, further makes him not blameworthy for being an out-group, thus inferior. His computer studies, in addition to his physical description, make the European reader feel admiration rather than contempt. It is proposed here that the positive representation of the stories of Sara and Ishmael is utilized to counter-represent the antagonized case of immigration. As explained earlier, the media's negative representation of the case is identified as fear and contempt for desperate immigrants. These two negative effects are intensified by the fact that immigrants constitute an out-group: non-Europeans. They neither share the Europeans, the in-group, their race nor culture, which makes it easy for the European audience to be affected by such a representation. The novel's positive representation of Sara and Ishmael and the recurrent evocation of death boats proposes a change of that negative affect into a positive one of interest and sympathy. This anticipated change, as explained earlier, will, hopefully, lead to decisions and action that resolve the crisis.

However, it is noted that the targeted affect, the one meant to be created in the novel, is that of sympathy rather than empathy. Readers get to know Sara and Ishmael through the focalization of other characters because their consciousness is never depicted. Sara's unfinished documentary project is introduced to the reader through the focalization of Christopher and Fran. Aim and preparation for this documentary are revealed to the reader when Christopher reflects on Sara's 
death. Many details of her life are left unknown because they are not contemplated on or mentioned either by Christopher or the other characters who know her. Hence, the reader sympathizes with Sara and her cause, but little chance is given to empathize with her because readers are never allowed access to her internal perspective. Ishmael, too, is never allowed a revelation of his thoughts and contemplations. Likewise, scarce details about Ishmael's homeland life, the voyage out of Africa, his intelligence . . . etc., are revealed by the focalization of Christopher, and the other characters who deal with him. Unlike the other European characters, either major or minor, whose thoughts are revealed in detail, Ishmael's are never spilt out. The reader is left to predict his internal perspective, guided by the views of the other characters on him and his action. Thus, access into the psyche of Ishmael (out-group) is facilitated by the focalization of European characters (in-group), which allows the reader to sympathize with him rather than empathize with him. This overall reliance on other characters' focalization obstructs readers' independent construction of Ishmael and Sara image because other characters' focalization is often subjective and marred by personal impressions and biases.

Furthermore, it is noticed that neither Sara nor Ishmael is engaged in dialogues with other characters. Both of them are deprived of two types of disclosure, defined by Phelan as, "conversational disclosure (what characters communicate to each other in a scene of dialogue) and authorial disclosure (what authors communicate to their audiences through the conversational disclosures)" ("Somebody"168). It is only once that we hear Sara commenting, with very few words, on food. Likewise, Ishmael is given one chance to be heard when he identifies, with very few words, the motor of a wrecked ship. Instead, there is a narrative shift from the mimesis of character-character dialogue to diegesis of narration. Direct communication between characters makes "agents acting independently of the narrator" (Phelan, "Somebody" 19). By depriving them of directly engaging in conversations with others, they are aesthetically denied an agency, though one is represented as an outgoing independent young woman, and the other is represented as an ambitious smart young man.

In addition, these disclosures, functioning like focalization, narrow the gap between characters and readers. Dialogues reveal characters' emotions, motives, knowledge, and include reference to personal experience, information about their social background. . .etc. For instance, a dialogue between Sara and other characters, especially Christopher, would reveal more about her; her motives for producing the documentary, her choice for the cause of immigration rather than other pressing causes, and whether her mixed-race has contributed to her adoption of the cause. Instead, readers' access to these illuminations, which would allow an opportunity to have an independent interpretation of characters, is obstructed.

It is suggested here that using a narrative method that simulates sympathy rather than empathy is attributed to targeting the reader's judgment. Sympathy, as 
mentioned earlier, is judgmental, thus it helps in raising readers' awareness of the undeserved suffering of immigrants, and the unfairness of their public and political rejection. This awareness helps in prompting a reconsideration of these negative attitudes. But Sara's position is different; she is never obliged to escape her country by resorting to death boats like Ishmael and his fellow immigrants. Sara's life mission of promoting immigration cause is noble, but she is not a victim. Meanwhile, Sara is of mixed origin, only half English, therefore she does not fulfil the conditionality of empathy, i.e., the necessity of being a member of in-group to simulate other fellow members' empathy. No matter how Sara adopts a Western lifestyle, still, the bonding cultural characteristics of in-group members are not attained in full respects. Out grouping Sara necessitates a narrative method that simulates sympathy, which, unlike empathy, indicates an emotional distance between her and in-group genuine Britons. This emotional distance is achieved by depriving Sara of focalization and disclosure of her conversations, which intersects the simulation of reader's empathy.

An ultimate aim of writing fiction is affecting a social transformation. Writers who aspire to achieve this noble end expose diverse human issues to raise readers' awareness of these issues. Attempting to simulate readers' sympathy and empathy is one way of building a bridge between them and characters, and, eventually, expanding their interest way beyond themselves. This bond is hoped to extend to include the suffering people in real life, which leads towards positive participation in solving their problems, thus, causing social change. Margaret Drabble's reputation as a social writer is reaffirmed in Dark Flood by her representation of the two pressing cases of ageism and illegal emigration. These cases are part and parcel of life in England, yet, it can be claimed that one is peculiar to the English people, and the other mainly touches the life of overseas nationals. Readers who do not share the identities or crises of the fictional characters can either sympathize or empathize with them, hence, these positive affects can expand to include in/out-groups in real life.

Dark Flood representation of the active elderly Fran draws attention to the need to include senior citizens in the making of the welfare of their country rather than marginalizing them by sending them to care homes, thus, blocking opportunities for their positive contribution. These seniors are categorized both as in-group and out-group. They are Britons who share the same cultural and racial identity as their fellow Britons. Yet, owing to their age group, they are considered physically unable to fully participate in everyday activities. On the other hand, the European (in-group) attitude of rejection of immigrants (outgroup) explains the main reason behind the immigration crisis. It also explains why immigrants are often unwelcomed by both media and populist governments; fear of cultural and racial differences intensifies the in-group's antagonism to the out-group. The novel's representation of cases of surviving immigrants such as Ishmael in a positive way prepares for setting right these negative attitudes. 
The study shows how the narrator controls readers' access into the inner life of these in-group and out-group characters. It shows how the scale of access allowed for readers to decide the type of created affect: sympathy or empathy. In investigating the narrator's handling of the inner lives of Ishmael and Sara on one hand, and that of Fran on the other, it is noticed that the scales of access to these different inner lives differ; one scale allows for sympathy, another allows for empathy. The study clarifies how each of these created emotional affects relates to the anticipated improvement of readers' attitudes towards these groups. Racial and cultural differences, which lead to categorizing fellow humans as out-group, can be either put aside or reconciled, by that distinguished role assigned to fiction. Within this context, the attitude of readers (in-group) towards the elderly (who constitute both in-group and out-group) and immigrants (out-group) can change from exclusion, distrust, and rejection to inclusion and acceptance. 


\section{Works Cited}

Ahern, Stephen. "Introduction: A feel for the Text." Affect Theory and Literary Critical Practice, edited by Stephen Ahern, Palgrave Macmillan, 2019, pp. 1-21.

Altmann, Ros. A New Vision for Older Workers: Retain, Retrain, Recruit. Department for Work and Pension, UK, 2015. https://publications.parliament.uk/pa/cm201719/cmselect/cmwomeq/359/ $\underline{359 . p d f}$

Bertrand Editora. Margaret Drabble apresenta «Sobe a Maré Negra» [Video]. You Tube. 8 Feb. 2019. https://youtu.be/HHwtnkIEZGA

Blake, Thomas. "Affective Aversion, Ethics, and Fiction." The Palgrave Handbook of Affect Studies and Textual Criticism, edited by Donald R. Wehrs and Thomas Blake, Palgrave Macmillan, 2017, pp. 207-234.

Brosius, Anna et al. "How media shape political trust: News coverage of immigration and its effects on trust in the European Union." European Union Politics, vol.20, no. 3, 2019, pp. 447-467.

Doi/10.1177/1465116519841706

Cikara, Mina and Jay J. Van Bavel. "The Neuroscience of Intergroup Relations: An Integrative Review." Perspectives on Psychological Science, vol. 9, no.3, 2014, pp. 245-274. https://doi:10.1177/1745691614527464

Cristea, Mirela et al. "The Impact of Population Aging and Public Health Support on EU Labor Markets." International Journal of Environmental Research and Public Health, vol.17, no. 4,1439, 2020. Doi:10.3390/ijerph17041439.

Cuddon, J. A. A Dictionary of Literary Terms and Literary Theory. WileyBlackwell, 2013. 
Danilova, Victoria. Media and Their Role in Shaping Public Attitudes Towards Migrants. OurWorldInData.org.2014. https://ourworld.unu.edu/en/mediaand-their-role-in-shaping-public-attitudes-towards-migrants

Dihal, Kanta. Amazing Affects: The Evocation of Affects in Science Popularizations for Children. 2014. Leiden University. MA dissertation. https://hdl.handle.net/1887/28665

Drabble, Margaret. The Dark Flood Rises. FSG, 2017.

Eberl et al. "The European media discourse on immigration and its effects: a literature review." Annals of the International Communication Association, vol. 42, no.3, 2018, pp. 207-223. DOI:10.1080/23808985.2018.1497452

Eisenberg, Nancy et al. "Relation of Sympathy and Personal Distress to Prosocial Behavior: A Multimethod Study." Journal of Personality and Social Psychology, vol. 57, no. 1, 1989, pp.55-66. DOI: 10.1037/00223514.57.1.55 .

Fernandez, José Francisco editor. The plays of Margaret Drabble: A Critical Edition. Syracuse UP, 2018.

Hardt, Michael. "Foreword." The Affective Turn, edited by Patricia Ticineto Clough and Jean Halley, Duke UP, 2007, pp. ix-xiii.

Hoffman, Martin L. "Empathy and Prosocial Behavior." Handbook of Emotions, edited by Michael Lewis et al. The Guilford Press, 2008, pp. 440-455.

Hogan, Patrick Holm. Understanding Nationalism: On Narrative, Cognitive science, and Identity. The Ohio State UP, 2009.

Hogan, Patrick Holm. "Affect Studies." Oxford Research Encyclopedia of Literature. 2016. Doi.org/10.1093/acrefore/9780190201098.013.105

Hogan, Patrick Holm. "Social Identity: Categorization, Cognition, 
and Affect." The Palgrave Handbook of Affect Studies and Textual Criticism, edited by Donald R. Wehrs and Thomas Blake, Palgrave Macmillan, 2017, pp. 183-205.

Keen, Suzanne. Empathy and the Novel. Oxford UP, 2007.

Kroon, Anne Cornelia et al. "Biased media? How news content influences age discrimination claims." European Journal of Ageing, vol. 16, 2019, pp.109-119. https://doi.org/10.1007/s10433-018-0465-4

Leys, R. "The Turn to Affect: A Critique." Critical Inquiry, vol. 37, no. 3, 2011, pp.434-472. https://doi:10.1086/659353

Munteanu, Dana LaCourse. "Empathy and Love: Types of Textuality and Degrees of Affectivity." The Palgrave Handbook of Affect Studies and Textual Criticism, edited by Donald R. Wehrs and Thomas Blake, Palgrave Macmillan, 2017, pp. 325-345.

Niven, Karen. "Affect." Encyclopedia of Behavioral Medicine, edited by Marc D. Gellman and J. Rick Turner, Springer, 2013, pp.49-50. https://doi.org/10.1007/978-1-4419-1005-9

Nussbaum, Martha. Upheavals of Thought: The Intelligence of Emotions. Cambridge UP, 2001.

Parliamentary Assembly. Resolution 1793 (2011), Promoting active ageingCapitalising on older people's working potential of 28 January 2011. http://website-pace. net/en_GB/web/apce/documents

Phelan, James. Experiencing Fiction: Judgments, Progressions, and the Rhetorical Theory of Narrative. The Ohio State UP, 2007.

Phelan, James. Somebody Telling Somebody Else: A Rhetorical Poetics of Narrative. The Ohio State UP, 2017.

Philpot, Don K. Character Focalization in Children's Novels. Palgrave Macmillan, 2017. 
Sklar, Howard. The Art of Sympathy in Fiction: Forms of Ethical and Emotional Persuasion. John Benjamin's Publishing Company, 2013.

Sklar, Howard. "Empathy's Neglected Cousin: How Narratives Shape Our Sympathy." The Palgrave Handbook of Affect Studies and Textual Criticism, edited by Donald R. Wehrs and Thomas Blake, Palgrave Macmillan, 2017, pp. 451-480.

Swift, H. J. et al. "Briefing paper: The perception of ageing and age discrimination." British Medical Association, 2016.

https://www.researchgate.net/publication/308970782_The_perception_of _ageing_and_age_discrimination 